\title{
A Anuência Prévia na Concessão de Patentes de Medicamentos e a Regulação Econômica DA INDÚSTRIA FARMACÊUTICA ${ }^{(*)}$
}

\author{
THE ADDITIONAL LAYER OF DRUG PATENT REVIEW BY ANVISA AND \\ THE ECONOMIC REGULATION OF PHARMACEUTICAL INDUSTRY
}

\author{
Sebastião Botto de Barros Tojal ${ }^{(\star \star)}$ \\ Patrícia Rodrigues Pessôa ${ }^{(\star \star \star)}$
}

\section{RESUMO}

A introdução do art. 229-C à Lei de Propriedade Intelectual (Lei n. 9.279/96), pela Lei n. 10.196/01, condicionou a concessão de patentes farmacêuticas pelo Instituto Nacional de Propriedade Intelectual (INPI) à anuência prévia da Agência Nacional de Vigilância Sanitária (Anvisa). O trabalho analisa duas competências distintas da agência: (i) para atuar no sistema de proteção intelectual; e (ii) para regular economicamente o mercado farmacêutico. Ao apresentar os mecanismos à disposição do Estado para o exercício da regulação dos preços dos medicamentos, demonstra-se a inadequação da patente para exercer a regulação econômica desse mercado.

\section{Palavras-chave}

Agência Nacional de Vigilância Sanitária; Controle de Preços; Direito Sanitário; Patente de Medicamentos.

(*) O presente artigo contou com a colaboração da estudante Karina Martins Araújo Santos, quem desenvolveu trabalhosa pesquisa a respeito da Câmara de Regulação do Mercado de Medicamentos (CMED), sua criação e competência. Recebido em 12.6.7. Aprovado em 14.8.7.

$\left({ }^{\star *}\right)$ Professor Doutor da Faculdade de Direito da Universidade de São Paulo, Professor do Curso de Especialização em Direito Sanitário da Faculdade de Saúde Pública da Universidade de São Paulo, Membro Fundador e Conselheiro do Centro de Estudos e Pesquisa de Direito Sanitário (CEPEDISA). E-mail: <st@ tsradvogados.com.br>.

$\left.{ }^{* \star \star}\right)$ Mestranda em Direito do Estado pela Faculdade de Direito da Universidade de São Paulo e Mestre pela London School of Economics and Political Science. E-mail:<prp@tsradvogados.com.br>. 


\section{ABSTRACT}

A change to Intellectual Property Statute 9.279/96 (by Bill n. 10.196/01) requires drugs patents to be approved not only by the patent office, the National Institute for Intellectual Property (INPI), but also by the National Drug Regulatory Agency (Anvisa). The paper analyses two different agency's power: (i) to take part of the intellectual property legal framework, and (ii) to exercise economic regulation over the pharmaceutical market. By setting out the tools at State disposal to regulate drug prices, this paper demonstrates how patents are inappropriate to regulate this market economically.

\section{Key words}

Drug Patents; Health Law; National Drug Regulatory Agency; Price Control.

\section{INTRODUÇÃO}

O debate em torno da regulação econômica da indústria farmacêutica ganhou novos contornos com a criação do instrumento da anuência prévia da Agência Nacional de Vigilância Sanitária (Anvisa) nos pedidos de concessão de patentes de produtos e processos farmacêuticos. A Lei n. 10.196, de 14 de fevereiro de $2001^{(1)}$, introduziu o art. 229-C à Lei de Propriedade Intelectual (Lei n. 9.279/96), condicionando a concessão de patentes farmacêuticas à anuência prévia da agência.

Se por um lado é de opinião unívoca que a Anvisa é a agência com competência legal para exercer o controle sanitário, inclusive da indústria de fármacos no Brasil, de outro, a racionalidade segundo a qual se baseia a participação da agência na proteção à propriedade intelectual apresenta caráter eminentemente econômico. Explica-se: parte da doutrina e por vezes a própria Anvisa preferem defender a anuência prévia como mecanismo de controle de preços. A proteção à saúde pública se daria na medida em que, por meio da anuência, a agência teria condições de controlar o preço dos novos produtos ingressantes no mercado farmacêutico. Contudo, sustentaremos no presente artigo que, com a criação da anuência prévia, a Anvisa passou a participar do processo de concessão de patentes farmacêuticas como maneira de garantir que o sistema de proteção intelectual seja compatível com a proteção à saúde pública e, frise-se, não quer isto dizer que o faz no exercício da sua competência para controlar preços dos medicamentos.

Partiremos da definição do papel da Anvisa como agente regulador da saúde pública no Brasil para, em seguida, tratarmos da concessão de patentes

(1) A Medida Provisória n. 2.105/2001 foi convertida na Lei n. 10.196, de 14 de fevereiro de 2001. 
farmacêuticas e, conseqüentemente, da questão relativa à anuência prévia. Nesta parte, tentaremos demonstrar que a introdução da agência no processo de concessão de patentes farmacêuticas tem como objetivo a preservação da saúde pública no sistema de proteção intelectual, ainda que apresente conseqüências econômicas relevantes.

Realizada a inserção da Anvisa no sistema de proteção intelectual, cumpre discorrer brevemente a respeito dos mecanismos à disposição do Estado, principalmente por meio da agência, para exercer a regulação econômica deste setor, como, por exemplo, controle e ajuste de preço de produtos e processos farmacêuticos. Percorrido o caminho apontado, acreditamos ter, de alguma forma, contribuído para aclarar o debate em torno da concessão de patentes farmacêuticas, tema sempre tão sensível à opinião pública.

\section{ANVISA, O AGENTE REGULADOR BRASILEIRO DA SAÚDE PÚBLICA}

Para analisarmos o moderno Direito Sanitário, é preciso retomar algumas premissas desenvolvidas outrora ${ }^{(2)}$, a começar pela inteligência da ordem econômica da Constituição de 1988. É de meridiana clareza que as normas constitucionais constantes do Título VII, especialmente no seu Capítulo I, imprimem a realização de uma nova ordem econômica e social cujo sistema econômico consagra a propriedade privada dos meios de produção. Este comando constitucional é afetado por um regime, que, se por um lado é aberto, de modo a acolher uma interpretação dinâmica e, principalmente, adequada à história do momento de sua realização, de outra banda assegura o papel de integração do sistema econômico de que é titular o Estado.

Soma-se a isso o entendimento de que a Constituição de 1988 é uma Constituição dirigente ${ }^{(3)}$, isto é, uma Constituição que não se contenta em definir um estatuto de poder, atuando como "instrumento de governo"; mas, vai além. Esta cuida igualmente de estipular programas e metas que deverão ser realizadas pelo Estado e pela sociedade.

(2) TOJAL, Sebastião Botto de Barros. A Constituição dirigente e o direito regulatório do Estado social: o direito sanitário. In: ARANHA, Márcio lorio; TOJAL, Sebastião Botto de Barros (Orgs.). Curso de Especialização à distância em Direito Sanitário para Membros do Ministério Público e da Magistratura Federal: Programa de Apoio ao Fortalecimento do Controle Social no SUS, Universidade de Brasília, Faculdade de Direito da UnB, Núcleo de Estudos em Saúde Pública da UnB/CEAM; Escola Nacional de Saúde Pública FIOCRUZ; REFORSUS; Ministério da Saúde.

(3) A noção de Constituição dirigente foi desenvolvida por José Joaquim Gomes Canotilho em sua tese de doutorado intitulada "Constituição Dirigente e Vinculação do Legislador - contributo para a compreensão das normas constitucionais programáticas", trabalho este paradigmático para a Teoria Constitucional. 
A partir do momento em que se consolida o modelo do Estado Social, especialmente à luz das considerações a propósito da ordem econômica da Constituição de 1988, o Direito assume o papel de fator implementador das transformações sociais, veiculando inclusive prestações públicas. Por conseqüência, opera-se uma rematerialização da racionalidade legal(4).

Especialmente no campo da saúde pública, é absolutamente imperativo reconhecer que a sua proteção se faz pela compreensão de que as normas típicas do que vem se definindo como o Direito Sanitário não se conformam aos modelos clássicos de um Direito concebido à luz de paradigmas estatutários, ou melhor, o Direito Sanitário como espécie do direito regulatório caracteriza-se, segundo Gunther Teubner, "pelo primado da racionalidade material relativamente à racionalidade formal"(5). Dito de outra maneira, é inerente ao processo de rematerialização da racionalidade legal o particularismo, a legitimidade determinada pela observância de critérios fundados numa ética de convicção a partir da qual os meios necessários são viabilizados para a consecução dos fins desejados.

Dessa forma, a garantia do direito à saúde, expressamente referida no art. 196 da Constituição, inscreve-se exata e precisamente no rol daquele conjunto integrado de ações de iniciativa dos Poderes Públicos, voltadas para a realização da ordem social, cujos objetivos são o bem-estar e a justiça sociais. Assim, a Constituição reconhece como de relevância pública as ações e serviços de saúde, cabendo ao Poder Público sua regulamentação, fiscalização e controle.

A Constituição de 1988, como uma constituição dirigente, é o comando a orientar a atuação do Estado para reduzir o risco de doenças, bem como garantir a todos, em igualdade de condições, o acesso às ações e serviços de promoção, proteção ou recuperação da saúde.

Com o advento das Leis Federais ns. 8.080/90 e 8.142/90(6), o Poder Público regulou o funcionamento dos serviços públicos assemelhados com vistas a promover, proteger e recuperar a saúde; além de instituir o Sistema

(4) Cf. Gunther Teubner: "Comparado com o clássico Direito formal, o direito material próprio da moderna era industrial assume desde logo uma nova função social. Tal direito não se limita a satisfazer os imperativos de resolução dos conflitos impostos pelo funcionamento de uma sociedade de mercado, mas serve também os imperativos políticos de intervenção e de direção próprios do moderno Estado-Social: quer dizer, o direito é instrumentalizado em função dos objetivos e finalidades do sistema político, que agora assume a responsabilidade pela condução de certos processos sociais, e nomeadamente, na definição dos objetivos a alcançar, na escolha dos instrumentos normativos, no processo de formulação e de implementação de normas." (TEUBNER, Gunther. Juridificação: noções, características, limites, soluções. Revista de Direito e Economia, Coimbra, p. 39, 1988).

(5) Id. Ibid., p. 49.

(6) As Leis Federais ns. 8.080/90 e 8.142/90 constituem a Lei Orgânica da Saúde (LOS), norma de caráter geral, elaborada no exercício da competência concorrente para disciplinar legalmente a proteção e defesa da saúde. 
Único de Saúde (SUS), organizando tais ações e serviços públicos em uma rede regionalizada e hierarquizada, cujas diretrizes são a descentralização, o atendimento integral e a participação da comunidade. Nesse contexto, o SUS é o primeiro a regular acerca da vigilância sanitária, conforme determina 0 art. 200 da CF e art. 6 da Lei n. 8.080/90. sanitária:

$O \S 1^{\circ}$ do art. $6^{\circ}$ da Lei n. 8.080/90 assim define a atividade de vigilância Art. $6^{\circ} \ldots$

$\S 1^{\circ}$ Entende-se por vigilância sanitária um conjunto de ações capaz de eliminar, diminuir ou prevenir riscos à saúde e de intervir nos problemas sanitários decorrentes do meio ambiente, da produção e circulação de bens e da prestação de serviços de interesse da saúde, abrangendo:

1 - o controle de bens de consumo que, direta ou indiretamente, se relacionem com a saúde, compreendidas todas as etapas e processos, da produção ao consumo; $e$

II - o controle da prestação de serviços que se relacionam direta ou indiretamente com a saúde.

Da definição legal de vigilância sanitária, decorre, entre outras, a noção de controle de bem de consumo que direta ou indiretamente se relacione com a saúde, compreendidas todas as etapas e processos, da produção ao consumo, a fim de eliminar, diminuir ou prevenir riscos à saúde, como é o caso dos produtos ou processos farmacêuticos.

O atual Sistema Nacional de Vigilância Sanitária (SNVS), definido pelo citado $\S 1^{\circ}$ do art. $6^{\circ}$ e pelos arts. 15 e 18 da Lei n. 8.080/90, conta com o auxílio da Agência Nacional de Vigilância Sanitária (Anvisa), a partir da edição da Lei Federal n. 9.782/99, para o exercício da competência da União no âmbito do SNVS. A finalidade institucional da Agência é promover a proteção à saúde da população, por intermédio do controle sanitário da produção e da comercialização de produtos e serviços submetidos à vigilância sanitária. O controle sanitário implica na fiscalização dos ambientes, dos processos, dos insumos e das tecnologias a eles relacionados, bem como o controle de portos, aeroportos e fronteiras.

Dito em outras palavras, no que concerne à atividade de controle sanitário de medicamentos, cabe à Anvisa garantir que produtos e processos farmacêuticos seguros e eficazes sejam disponibilizados aos consumidores, impedindo a comercialização daqueles que, por motivos técnicos de farmacologia, apresentem perigo à saúde pública. Para tanto, o instrumento de registro de produtos e processos farmacêuticos está à disposição da Agência (art. IX, art. $7^{\circ}$ da Lei n. 9.782/99) ${ }^{(7)}$.

(7) A respeito do registro de medicamentos pela antiga Agência Nacional de Vigilância Sanitária (ANVS) e atual Anvisa: "A finalidade comercial do pedido de registro perante a ANVS, além de 
Além disso, o controle de produtos e processos farmacêuticos exercido pela Anvisa deve visar à redução da assimetria de informação existente no setor farmacêutico, diminuindo a diferença nos níveis de informação na cadeia indústria-prescritor-farmácia-paciente. Pois, de um lado verifica-se a assimetria no mercado de medicamentos comercializados sob prescrição médica, isto é, entre a indústria responsável pela pesquisa, criação, processamento e comercialização de novas drogas, e os médicos que prescrevem os medicamentos ao paciente. De outra banda, configura-se a assimetria no mercado de medicamentos conhecido como Over The Counter (OTC), cuja comercialização prescinde de prescrição médica, entre a indústria, a farmácia e o consumidor final.

\section{A CONCESSÃO DE PATENTE DE PRODUTOS E PROCESSOS FARMACÊUTICOS}

Não faz muitos anos, a concessão de patente para produto e processos farmacêuticos era considerada instrumento de abuso contra a saúde pública. Tanto era assim que o Brasil, com a antiga lei de propriedade intelectual (Lei n. 5.772/71), não previa a possibilidade de concessão do direito à exclusividade patentária a processos e produtos farmacêuticos, ao lado de produtos alimentícios e químicos ${ }^{(8)}$.

Todavia, o tom da proteção intelectual no Brasil foi alterado com a Constituição de 1988. Além da garantia aos autores do privilégio temporário para a utilização dos inventos industriais e da proteção às criações, à propriedade das marcas, aos nomes das empresas e a outros signos distintivos, a ordem constitucional vigente passou a limitar tais garantias e proteções ao interesse social e contributivo para o desenvolvimento tecnológico e econômico do país (art. 5ำ XXIX).

A partir das novas diretrizes estabelecidas por uma Constituição dirigente, como é a Constituição de 1988, a Lei n. 9.279/96 (Lei de Propriedade Intelectual ora vigente) foi promulgada, autorizando não só a concessão de patentes para todos os setores tecnológicos, como inclusive para o farmacêutico. A partir daí, afastou-se a discussão acerca do benefício ou malefício

óbvia, está evidenciada na própria legislação da vigilância sanitária. O único objetivo, o fim almejado, com o procedimento de registro de produto (novo, similar ou genérico) é a possibilidade de vender medicamentos no país de forma lícita" (LICKS, Otto. Registro de medicamentos genéricos na ANVS e infração de patentes. Revista da $A B P I$, Rio de Janeiro, n. 45, p. 33, mar/abr. 2000).

(8) Vide art. $9^{\circ}$, letra $c$ da Lei n. 5.772/71. A título de curiosidade, vale comentar que a Constituição Imperial (art. 179, XXVI) já regulava a propriedade intelectual no país. De 1945 a 1969 o país concedia patente apenas para processos farmacêuticos, negando-as para produtos, e com a referida Lei n. 5.772/71, foi eliminada a concessão de privilégios também aos processos farmacêuticos. Sobre os efeitos gerados pela proibição de patentes a remédios e processos farmacêuticos, vide LYARD, Maria Alice Paim. Patentes de Medicamentos, questões atuais. Revista da ABPI, Rio de Janeiro, n. 82, p. 29-30. 
da concessão de patentes para produtos ou processos farmacêuticos. A concessão de patente, como direito à exclusividade de produzir e comercializar determinado produto ou processo farmacêutico por 20 (vinte) anos é considerada, portanto, uma recompensa ao inventor, incentivando-o a persistir na pesquisa e desenvolvimento de novas invenções.

Nesse passo, a proteção da propriedade intelectual passa a não ser um fim em si mesmo, mas um meio para se atingir um objetivo. Este é um ponto central, pois por vezes aqueles portadores de direitos patentários, grupos de interesses, perdem de vista que o pilar da proteção da propriedade intelectual é promover o desenvolvimento econômico e o comércio internacional e não proteger interesses particulares de determinado grupo ${ }^{(9)}$. Mesmo porque imaginar o contrário seria ignorar os mecanismos já previstos no sistema de proteção à propriedade intelectual para coibir o uso indevido das patentes pelos seus detentores.

A Lei de Propriedade Intelectual prevê a licença compulsória como um mecanismo de limitação à propriedade industrial, aplicando-se sempre que este direito estiver sendo exercido de forma abusiva ou com abuso do poder econômico (art. 68, caput), ou quando seu detentor não tiver explorando devidamente o seu objeto (art. 68, I) ou, ainda, quando a sua comercialização não estiver satisfazendo as exigências de mercado (art. 68, II).

$\mathrm{Na}$ área de acesso aos medicamentos e à saúde pública em face da proteção patentária, merece destaque especial a Declaração de Doha ${ }^{(10)}$ Este documento esclarece que a gravidade de alguns problemas que afetam muitos países em desenvolvimento ou menos desenvolvidos merece ser considerada no âmbito da conclusão do Acordo sobre Direitos de Propriedade Intelectual relacionados ao Comércio ao final da rodada do Uruguai (Acordo TRIPS) ${ }^{(11)}$. Assim, os países signatários corroboram entre si que "os Acordos TRIPS não devem impedir os Estados-membros de tomar medidas para proteger a saúde pública. $E$ ainda que reiterando nosso interesse nos mencionados Acordos, afirmamos que os mesmos podem e devem ser interpretados e implementados de forma a apoiar o direito dos membros da OMC a proteger a saúde pública e, em particular, a promover o acesso dos medicamentos para todos. Neste sentido, reafirmamos o direito dos Membros da OMC de fazer uso, em toda a sua plenitude, da flexibilidade implícita nas disposições do Acordo TRIPS para tal fim"(12).

(9) Cf. UNCTAD/ICTSD - Resource Book on TRIPS. Part one: nature of obligations, principles and objectives. October, 2002, Geneve.

(10) A Declaração de Doha foi assinada em novembro de 2001 no âmbito da Organização Mundial do Comércio (Declaração sobre o Acordo de TRIPS e Saúde Pública; IV Conferência Ministerial da OMC).

(11) O acordo é comumente referido pela sigla composta pelas iniciais do nome em inglês, "Trade Related Aspects of Intellectual Property Rights". O Decreto n. 1.355, de 30 de dezembro de 1994 promulgou o Acordo TRIPS no Brasil.

(12) Item 4 da Declaração de Doha. 
Como se verificou, a legislação nacional em conformidade com os instrumentos internacionais coloca à disposição do Poder Público mecanismos para a adequada e salutar aplicação da proteção patentária, de forma a não prejudicar a proteção ao direito à saúde em cada um dos Estados signatários. Esta iniciativa internacional teve como ponto de partida o reconhecimento pela comunidade mundial dos problemas de saúde e a incapacidade de aquisição e desenvolvimento de medicamentos para o adequado tratamento de epidemias como HIV/AIDS, tuberculose e malária que afligem os países em desenvolvimento ou menos desenvolvidos.

Assim, no setor farmacêutico, o estímulo à pesquisa e desenvolvimento por meio das patentes é considerado determinante para que as indústrias continuem buscando novas invenções, tratamentos inovadores e garantias de adequada aplicação dos medicamentos destinados ao consumo humano. Contudo, conforme observam Calixto Salomão Filho, Maristela Basso e Fabrício Pasquot Polido(13), "se por um lado (o monopólio de produção e exploração industrial das patentes farmacêuticas) objetiva assegurar que recursos sejam investidos em pesquisa e tecnologia, por outro acaba por encarecer os medicamentos". Em tema de patentes farmacêuticas, a questão do preço do remédio colocado à disposição do consumidor é sempre reconhecida como conseqüência indissociável da concessão da patente para a empresa farmacêutica que investiu na pesquisa e desenvolvimento daquela droga ou técnica nova colocada à disposição.

A Anvisa(14) não ficou atrás. A Agência também reconheceu o aumento dos preços dos medicamentos como decorrentes da concessão da patente. Em documento oficial afirma:

"Vale lembrar que quando a patente é concedida o seu detentor passa a ter direitos exclusivos de exploração do objeto protegido (produção, utilização, comercialização sem concorrência, venda ou importação) pelo período de 20 anos. Por isso, a necessidade de análise criteriosa dos requisitos para a concessão de tal benefício, tendo sempre em conta que esta proteção pode se refletir diretamente no custo final do medicamento."

Não se cuida, destarte, de negar pedido de patente de produto ou processo farmacêutico com fundamento na conseqüência de que sua concessão

(13) SALOMÃO FILHO, Calixto; BASSO, Maristela; POLIDO, Fabrício Pasquot. Propriedade intelectual e preços diferenciados de medicamentos essenciais: políticas de saúde públicas para países em desenvolvimento. RDPE, Belo Horizonte, ano 3, n. 11, p. 77, jul./set. 2005. Neste artigo os autores defendem uma política de preços diferenciados sobre medicamentos essenciais e introduzem a idéia de que "o direito à patente ou à marca não mais pode ser vista como mera propriedade ou privilégio de seu titular. Entendido como meio de tutelar a concorrência (no sentido institucional), assume a função principal de garantir o acesso e escolha dos consumidores" (p. 75). (14) "Política Vigente para a Regulamentação de Medicamentos no Brasil", Anvisa, realização: Gabinete do Diretor-Presidente, 2004. 
acarretaria aumento no preço daquele remédio. Apesar da facilidade com que se relaciona concessão de patente e aumento do preço de medicamentos, pouco se aborda a respeito da regulação, formação e ajuste do preço de medicamentos, tema que abordaremos após a análise da figura da anuência prévia. A partir do estudo da regulação econômica do mercado de medicamentos verifica-se a existência de instrumentos, que não a patente, à disposição do Estado, inclusive da Anvisa, para controle dos preços dos medicamentos.

\section{A INSERÇÃO DA ANVISA NO SISTEMA DE PROPRIEDADE INTELECTUAL}

Antes de adentrar na análise da figura da anuência prévia a cargo da Anvisa, é indispensável abordar o papel do Instituto Nacional de Propriedade Intelectual (INPI). Esta autarquia federal, vinculada ao Ministério do Desenvolvimento, Indústria e Comércio Exterior, é responsável pela concessão dos registros de marca ou de desenho industrial e das patentes de invenção ou de modelo de utilidade previstas na Lei n. 9.279/96, tendo em vista sua função social, econômica, jurídica e técnica (nos termos do art. $2^{\circ}$ da Lei n. 5.648/70).

O procedimento administrativo perante o INPI para concessão de patente implicava, até a introdução da Anvisa para os casos de patentes de produtos ou processos farmacêuticos, na execução de ato vinculado. Ou seja, preenchidos os requisitos da lei, o inventor tem direito constitucional à patente. Contudo, com o advento da anuência prévia, não só estamos diante de um ato administrativo complexo, o qual exige a participação de mais de um ente da administração, como, principalmente, o ato passa a ser discricionário no que tange à participação da Agência, conforme passaremos a expor.

Diante da introdução da Anvisa no processo de concessão de patentes farmacêuticas, o INPI deliberou, por meio de sua Diretoria de Patentes, encaminhar à Agência os pedidos de patente de produtos ou processos farmacêuticos antes de seu deferimento pelo Instituto, condicionando a publicação do despacho de deferimento à anuência formal do agente regulador da vigilância sanitária(15).

Ocorre que, ao introduzir o instrumento da anuência prévia em nosso ordenamento jurídico, o legislador não explicitou seus contornos na Lei $n$. $10.196 / 01$. Tampouco houve a edição de decreto presidencial para regulamentar o art. 229-C da Lei de Propriedade Intelectual. Destarte, diante da omissão do poder regulamentar do Governo Federal, está posta a instabilidade na resolução de conflitos, inclusive na esfera judicial, em pedidos de patente para produtos e processos farmacêuticos.

(15) Comunicado INPI/DIRPA 02/2001, expedido pela Diretoria de Patentes do INPI em 2 de abril de 2001. 
Por ora, enquanto o decreto presidencial não apresenta soluções às questões colocadas, resta-nos interpretar sistematicamente a legislação aplicável ao instrumento da anuência prévia, não só com vistas a harmonizar a competência da agência de participar da concessão de patentes farmacêuticas com suas outras atribuições legais, bem como compatibilizar a atuação conjunta, e a nosso ver complementares, da Anvisa e do INPI. Assim, propomos três elementos caracterizadores deste novo instrumento.

O primeiro elemento da anuência prévia é que esta deve se dar no limite da sua competência. Isto é, somente pode versar a respeito de aspectos atinentes à proteção da saúde pública e não sobre critérios de patenteabilidade de competência restritamente do INPI. Dessa forma, a Anvisa extrapolaria sua competência caso recusasse anuência com fundamento na falta de requisitos que devem ser apreciados com exclusividade pelo INPI.

Sendo assim, eventual recusa da Anvisa somente será aceita, do ponto de vista legal, na hipótese em que seu fundamento demonstre que a decisão tomada reflete a persecução da finalidade da agência: proteção à saúde pública por meio do controle sanitário. Dito em outras palavras, recusa de anuência que tenha como motivação argumentos diversos, ainda que pertinentes aos critérios da Lei de Propriedade Intelectual, não se demonstrará compatível diante da repartição legal de competências.

Defender entendimento contrário seria ignorar o princípio da legalidade para agentes da Administração Pública, os quais só podem agir no limite das suas competências legais. Ao passo que a Lei n. 9.279/96 concede ao INPI a competência para verificar o atendimento aos requisitos da novidade, atividade inventiva e aplicação industrial (art. 19), a Lei n. 9.782/99 definiu o SNVS e criou a Anvisa com a finalidade principal para "promover a proteção da saúde da população, por intermédio do controle sanitário da produção e da comercialização de produtos e serviços submetidos à vigilância sanitária, inclusive dos ambientes, processos dos insumos e das tecnologias a eles relacionados, bem como o controle de portos, aeroportos e fronteiras" (art. 6º).

Não se pode perder de vista que antes de atribuir ao instrumento da anuência prévia vícios de ilegalidade, é necessário analisar as competências de cada um dos órgãos públicos diretamente envolvidos, a fim de buscar a harmonização das competências entre o INPI e a Anvisa. A esse respeito, Professor Edson Beas Rodrigues Junior assinala: "enquanto o INPI se encarrega precipuamente da análise do preenchimento dos requisitos de patenteabilidade bem como de outras formalidades de procedimento, a Anvisa se encarrega de aspectos próprios de saúde pública, interesses esses não contemplados na análise do INPI. Logo, tecnicamente, a função dos dois órgãos se justifica e são complementares." (16)

(16) Não obstante discordamos da opinião defendida pelo professor em alguns pontos, parece-nos de suma importância a proposta de repartição de competência entre o INPI e a Anvisa consubstanciada no artigo "Anuência prévia: integração do direito à saúde aos direitos de propriedade intelectual", in Revista dos Tribunais, 840/103-104. 
A esta repartição de competência acrescentamos que o INPI poderia, antes da criação do instrumento da anuência prévia, negar a patente com fundamento na proteção da saúde pública, com base no art. 18, I, da Lei de Propriedade Intelectual. Com o art. 229-C da Lei de Propriedade Intelectual, acreditamos se tratar de competência agora a ser exercida pela Anvisa, o que nos leva ao segundo elemento.

O segundo elemento material caracterizador da anuência prévia é a tecnicidade da decisão a ser tomada pela agência, seja a anuência favorável ou contrária à concessão da patente. $O$ processo decisório da Anvisa, esta como agente regulador da vigilância sanitária, se faz no exercício da discricionariedade técnica. A racionalidade da decisão da agência deve ser fundamentalmente técnica, a justificar a expertise do agente regulador ${ }^{(17)}$.

Citando Massimo Severo Giannini (discricionariedade técnica), Diogo de Figueiredo Moreira Neto(18) afirma:

"Assim é que nos casos em que a lei prescreve à Administração uma atividade de aclaramento da realidade tecnicamente complexa que importa no emprego de disciplinas especializadas, ou mesmo nos casos em que esse aclaramento for necessário ao exercício do poder, esta doutrina (criticável, porém consolidada) considera atribuído um verdadeiro e adequado poder discricionário (de conteúdo técnico).

"Em razão do exposto, o conteúdo válido das normas baixadas pelas agências reguladoras, das quais a de vigilância sanitária é um adequado exemplo, está integralmente definido na margem de escolha técnico-científica que a legislação delegante abriu à exclusiva discrição dos respectivos agentes técnicos.

"Ultrapassar tais limites, ao acrescentar às normas reguladoras critérios político-administrativos onde não deveriam existir, caracteriza a invasão de poderes que são próprios à esfera das decisões do Poder Legislativo e propositadamente retirados dos agentes da burocracia administrativa direta."

(17) Floriano de Azevedo Marques ao defender que a legitimidade dos órgãos reguladores terá que se dar menos pela presunção da supremacia e inoponibilidade do poder estatal (poder extroverso) e mais por elementos, entre os quais, a detenção do conhecimento técnico aplicável ao setor, conforme segue: "O que se faz relevante, contudo, é que os órgãos reguladores dominem profundamente a expertise do setor, evitando que esse conhecimento específico fique acervado apenas com os operadores da atividade regulada. Daí por que uma das funções mais relevantes de uma agência é a formação de agentes reguladores, o desenvolvimento de um conhecimento regulatório próprio." $E$ ainda sugere que "isto deve ser obtido mediante a contratação de consultorias externas (que the agreguem know-how) e com o estabelecimento de acordos e convênios com instituições de ensino e pesquisa aptas a formar novos quadros para o setor. (MARQUES, Floriano de Azevedo. A nova regulação estatal e as agências independentes. In: SUNDFELD, Carlos Ari (Org.). Direito administrativo econômico. São Paulo: Malheiros Ed.; SBDP, 2002. p. 91-97).

(18) MOREIRA NETO, Diogo de Figueiredo. Reinstitucionalização da ordem econômica no processo de globalização. Cadernos de Direito Constitucional e Ciência Política, Sao Paulo, v. 5, n. 18, p. 87-95, jan./mar. 1997. 
Ademais, a discricionariedade técnica está circunscrita tão-somente à área de competência da agência de vigilância sanitária, uma vez que a discricionariedade técnica (tecnicidade como racionalidade da decisão) decorre da expertise do agente regulador. Assim, não é permitido à Anvisa, a pretexto de realizar análise técnica, adentrar na verificação dos requisitos de patenteabilidade, competência própria do INPI. Da análise das competências de cada ente, a anuência prévia não autoriza, no exercício da discricionariedade técnica, a análise de aspectos alheios à saúde pública, como é o caso dos requisitos de patenteabilidade.

A esse respeito, a Associação Brasileira da Propriedade Intelectual (ABPI) editou a Resolução ABPI n. 16/2001 que corrobora o entendimento apontado acima:

"(2) Sob hipótese alguma a ANVISA poderá apreciar ou mesmo rever os requisitos de patenteabilidade contemplados no art. $8^{\circ}$ da Lei n. 9.279/96, a saber, novidade, atividade inventiva e aplicação industrial. A ANVISA também não poderá examinar o cumprimento das formalidades relativas ao depósito do pedido de patente. Não há nenhum dispositivo na Lei $n .10 .196$ ou na Lei n. 9.782/99 que Ihe atribua estas tarefas, que sempre foram desempenhadas pelo INPI;

“3) Os arts. $6^{\circ}$ e $8^{\circ}, \S 1^{\circ}$, inciso I, da Lei n. 9.782/99 conferem à ANVISA o controle sanitário de produtos farmacêuticos, inclusive no que se refere ao processo de fabricação e às tecnologias a eles relacionadas. Desta forma, a participação da ANVISA na concessão de patentes relativas a produtos ou processos farmacêuticos relaciona-se apenas e tão-somente com o disposto na parte final do art. 18, inciso I, da Lei n. 9.279/96 e no art. 27.2 do TRIPS, de modo a verificar se o pedido de patente de invenção ou modelo de utilidade é em si atentatório à saúde pública;"...

Caso a discricionariedade técnica não fosse tão particular da Anvisa, não haveria motivos para a criação do instrumento da anuência prévia, uma vez que, como dito anteriormente, a própria Lei de Propriedade Intelectual já previa a possibilidade de rejeição do pedido de patente por ofensa à saúde pública (art. 18, I, da Lei n. 9.279/96).

A cumulação do primeiro elemento da anuência (competência da Anvisa para tratar apenas e tão-só da proteção à saúde pública) com o segundo (discricionariedade técnica da Anvisa), leva-nos a concluir que o exercício da discricionariedade técnica própria da Anvisa deve ser utilizada somente quando se tratar de matéria relativa à proteção da saúde pública, sob pena de exorbitar sua competência legal.

O terceiro elemento que caracteriza a anuência da Anvisa é seu caráter não determinante na formação da decisão final do INPI. Ainda que a Anvisa anua com a concessão da patente para determinado medicamento, o INPI tem a possibilidade de negar o pedido, caso o Instituto entenda que os requisitos de patenteabilidade não foram atendidos. Conseqüência disto é que a anuência da Anvisa não esgota o processo de concessão de patente 
de produtos e processos farmacêuticos. No entanto, o inverso não se verifica. Sendo o parecer da Anvisa pela negativa da concessão da patente, não pode o INPI decidir pelo contrário.

Isto posto, considerando que a anuência está limitada à competência da Anvisa, e que esta decisão da agência deve ser revestida de tecnicidade (quer seja para negar ou conceder a anuência na concessão de patentes farmacêuticas) e não é determinante na formação da decisão final do INPI, uma vez que este pode negar a patente por outros motivos, é possível identificar certa harmonia entre as competências do INPI e da Anvisa. Identificado isso, a seguir discorreremos a respeito da competência da agência para realizar a regulação econômica do mercado farmacêutico.

\section{REGULAÇÃO ECONÔMICA DO MERCADO FARMACÊUTICO, FORMAÇÃ̃O E AJUSTE DE PREÇOS DOS MEDICAMENTOS}

A regulação econômica do setor farmacêutico a cargo da Anvisa, ressalte-se, não encontra aplicação no exercício da anuência prévia em pedidos de concessão de patente farmacêutica. Pelo contrário: tal regulação vem sendo feita por outros mecanismos (certamente mais hábeis que a anuência prévia e a concessão de patentes) no controle da oferta de produtos e processos farmacêuticos para os consumidores (farmácias e usuários) e, principalmente, do preço ofertado pelos fabricantes ao usuário, consumidor final. É indiscutível que é dever do Poder Público desenvolver tais mecanismos capazes de impedir o abuso do poder de mercado na forma de imposição de preços por parte da indústria e isso tem sido feito.

A prática de infrações contra a ordem econômica, assim definida pelo art. 20 da Lei n. 8.884/94, é coibida pelo Conselho Administrativo de Defesa Econômica (CADE), no uso de suas atribuições legais. Assim, serão repreendidos e, quando possível, evitados os atos sob qualquer forma manifestados, que tenham por objeto ou possam produzir efeitos de limitar, falsear, ou prejudicar a livre concorrência ou livre iniciativa; dominar o mercado relevante de bens ou serviços; aumentar arbitrariamente os lucros; ou ainda exercer de forma abusiva posição dominante, pelo CADE.

Além disso, as experiências estrangeiras trazem outra gama de opções de medidas com vistas a evitar o aumento arbitrário e abusivo dos preços dos medicamentos e possibilitar o acesso da população aos medicamentos básicos, como por exemplo, o financiamento público. Segundo dados da própria Anvisa, a maioria dos países da OCDE exerce regulação sobre os preços dos medicamentos por meio da definição de um sistema de inclusão de produtos nas listas de produtos passíveis de cobertura parcial ou 
total pelo sistema público de saúde. O Poder Público usa seu poder de barganha de grande comprador para contrabalançar o poder de mercado da indústria farmacêutica ${ }^{(19)}$.

No Brasil, temos a Política Nacional de Medicamentos ${ }^{(20)}$ elaborada a partir de amplo processo de discussão, do qual participaram diversos segmentos relacionados ao tema, e aprovada pela Comissão de Intergestores Tripartite e pelo Conselho Nacional de Saúde. Vinculada aos princípios e diretrizes do SUS e acolhendo as recomendações da Organização Mundial de Saúde (OMS), é um facilitador aos mais carentes na obtenção dos medicamentos necessários, além de aperfeiçoar a distribuição no setor público. Diz a citada política que seus objetivos são "garantir a necessária segurança, eficácia e qualidade destes produtos, a promoção do uso racional e o acesso da população àqueles considerados essenciais"(21).

Para adequar a oferta de medicamentos às necessidades do país, adotou-se a Relação Nacional de Medicamentos Essenciais (Rename) a qual traz elenco de produtos necessários ao tratamento e controle da maioria das patologias prevalentes no país. Tais medicamentos devem estar continuamente disponíveis para a população que deles necessita. Para a atualização periódica da Rename, o Ministério da Saúde (Portaria GM n. 131/01) constituiu a Comissão Técnica e Multidisciplinar de Atualização da Relação Nacional de Medicamentos Essenciais (Comare), composta por algumas instituições e órgãos envolvidos com o tema medicamentos, tais como o Minstério da Saúde, a Anvisa e a Sociedade Brasileira de Vigilância de Medicamentos (Sobravime).

No que se refere especificamente ao controle de preços dos medicamentos, a Lei n. 10.742/03 criou a Câmara de Regulação do Mercado de Medicamentos (CMED), órgão do Conselho de Governo(22), estruturada a partir do Conselho de Ministros (formado pelo Ministro da Saúde, Chefe da Casa Civil, Ministro da Justiça e Ministro da Fazenda) e do Comitê TécnicoExecutivo (formado pelos Secretário de Ciência e Tecnologia e Insumos Estratégicos do Ministério da Saúde, Secretário-Executivo da Casa Civil, Secretário de Direito Econômico do Ministério da Justiça e Secretário de Acompanhamento Econômico do Ministério da Fazenda). À Anvisa coube a secretaria executiva da CMED ${ }^{(23)}$.

(19) Os EUA não adotam esta política regulatória. Neste país, observa-se a criação de sistemas privados de financiamento, segundo o qual os medicamentos estariam cobertos pelos planos de saúde privados em farmácias conveniadas (cf. REGULAÇÃO econômica do mercado farmacêutico. Brasília: Anvisa, Brasília, maio 2001).

(20) Portaria n. 3.916/MS/GM, de 30 de outubro de 1998.

(21) Para a definição e as funções dos preços diferenciados de medicamentos essenciais e sua importância nas iniciativas de ações afirmativas e políticas públicas, consultar SALOMÃO FILHO, Calixto; BASSO, Maristela; POLIDO, Fabrício Pasquot. op. cit., p. 63-97.

(22) Integrante da Casa Civil, o Conselho de Governo é órgão de assessoramento imediato do Presidente da República (Lei n. 9.649, de 27 de maio de 1998 e MP n. 2.216-37/2001).

(23) A Anvisa exerce a Secretaria Executiva da CMED conforme regulamentam o Decreto n. 4.766, de 26 de junho de 2003 e o Regimento Interno da Câmara (Resolução CMED n. 3, de 29 de julho de 2003). 
A missão da CMED é adotar, implementar e coordenar as atividades relativas à regulação econômica do mercado de medicamentos, com vistas à promoção da assistência farmacêutica à população, por meio de mecanismos que estimulem a oferta de medicamentos e a competitividade no setor ${ }^{(24)}$.

Com ampla competência para desempenhar a regulação econômica do setor farmacêutico, a CMED estabelece critérios para a fixação de preços de medicamentos já disponíveis no mercado e de novas apresentações e medicamentos, bem como decide pela exclusão e inclusão de grupos, classes e subclasses de medicamentos e produtos farmacêuticos da incidência dos critérios de estabelecimento ou ajuste de preços $^{(25)}$.

Os parâmetros para formação e ajustes dos preços estão estabelecidos pela Lei n. 10.742/03 e aplicados nas diversas Resoluções da CMED editadas desde sua criação. Desta forma, o preço de novos produtos ou novas apresentações de medicamentos é definido a partir das categorias discriminadas e respectivos critérios, os quais variam entre a média do Preço de Fábrica (PF) praticado em outros países e o PF permitido para medicamentos (ou apresentações) utilizados para a mesma indicação terapêutica, além de outros conforme determina a Resolução CMED n. 2, de 5 de março de 2004.

Os ajustes de preços ocorrem anualmente no mês de março segundo modelo de teto de preços calculado com base no IPCA (fonte IBGE), em um fator de produtividade e um fator de ajuste de preços relativos intra-setor $\mathrm{e}$ entre setores, sendo que cada um desses índices será definido pela CMED. Esclarece a lei que o índice de produtividade é mecanismo que permite repassar aos consumidores, por meio dos preços dos medicamentos, projeções de ganhos de produtividade das empresas produtoras de medicamentos. Já o índice de preços relativos, aspecto mais concorrencial, divide-se em duas parcelas: (i) preços relativos intra-setor, calculada com base no poder de monopólio, na assimetria de informação e nas barreiras à entrada; e (ii) preços relativos entre setores, calculada com base na variação do custo dos insumos, excluídos os custos computados pelo IPCA ${ }^{(26)}$.

(24) Ainda que pese a recente criação da CMED, a extinta Câmara de Medicamentos, instituída pela Lei n. 10.213/01 exercia competências similares. A Câmara de Medicamentos foi extinta pela Lei n. 10.742/03.

(25) Estão dispensados dos critérios de ajuste e determinação de preços três classes de medicamentos: (i) os medicamentos fitoterápicos e homeopáticos; (ii) os medicamentos listados no anexo da Resolução CMED n. 5, de 9 de outubro de 2003; e (iii) as novas apresentações que o Comitê Técnico-Executivo reconhecer como similares às constantes da lista da Resolução CMED n. 5, de 9 de outubro de 2003, conforme disposição da Resolução CMED n. 3, de 15 de março de 2004.

(26) Decreto n. 4.937, de 29 de dezembro de 2003. 
Posta assim a questão, é de se salientar mais uma vez que diante das normas que regulam economicamente o setor farmacêutico, isto é, a necessidade de registro do medicamento para a regular comercialização e a fixação e ajuste de preços determinados pelo Poder Público, demonstram que o Estado vem exercendo a regulação econômica por mecanismos específicos, desenvolvidos com esta finalidade.

É preciso insistir no fato de que o Estado (no caso a Anvisa como secretária-executiva da CMED) dispõe de instrumentos para controlar preços de medicamentos, delimitados no exercício da sua competência legal e regulamentar, ao largo de outras políticas regulatórias que não foram objeto do presente artigo. Disso decorre que o Estado, como agente regulador, criou mecanismos apropriados para o atendimento das metas propostas. Contudo, outra competência foi conferida à Anvisa: a anuência prévia. Esta, ao contrário dos instrumentos de controle de preço, é voltada para a compatibilização da proteção intelectual com a proteção à saúde pública.

\section{CONCLUSÕES}

Logo nas considerações iniciais do presente artigo, mencionamos o entendimento aqui combatido de que o instrumento da anuência prévia da Anvisa aos pedidos de concessão de patentes farmacêuticas serviria para que esta Agência pudesse também exercer o controle de preços neste setor.

Da idéia de Direito Sanitário regulador fundado a partir de ditames de uma ordem constitucional dirigente, conclui-se que o dever estatal em implementar as ações e disponibilizar os serviços de saúde reveste-se de relevância pública. A Anvisa, inserida no Sistema Nacional de Vigilância Sanitária e como agente regulador desse setor, tem por finalidade promover a proteção à saúde da população por intermédio do controle sanitário.

O sistema de proteção intelectual vem a se conformar com o Direito Sanitário regulador. Antes mesmo do advento da anuência prévia, o sistema, por meio das normas nacionais (Lei de Propriedade Intelectual) e internacionais (acordo TRIPS e Declaração de Doha), já previa limitações ao uso indevido ou até mesmo conseqüências não desejadas pelos países signatários dos tratados internacionais (e. $g$. a licença compulsória de patentes farmacêuticas para países em desenvolvimento).

Com a introdução do art. 229-C na Lei de Propriedade Intelectual, a Anvisa passou a aplicar o comando constitucional de realizar o controle sanitário também mediante análise dos pedidos de concessão de patentes farmacêuticas. Assim, propusemos três elementos caracterizadores da anuência prévia: (i) a anuência está limitada à competência da Anvisa; (ii) a tecnicidade da decisão da agência para negar ou conceder a anuência na concessão de patentes farmacêuticas; e, por fim, (iii) o caráter não determinante na formação da decisão final do INPI. 
A figura da anuência prévia no processo de concessão de patente de produtos ou processos farmacêuticos, somados aos demais mecanismos já existentes das regras relativas à proteção patentária, compõe sistema de proteção da propriedade intelectual compatível com a proteção da saúde pública, tal como a mais rasa interpretação sistemática da ordem constitucional vigente determinaria.

Afinal, exigir da patente a proteção da saúde pública é o mesmo que exigir do Estado que tenha optado pelo instrumento errado para o resultado pretendido ${ }^{(27)}$. Pois, as patentes não têm o alcance necessário para solucionar questões atinentes à saúde pública, merecendo reconhecimento na sua aplicação para o incentivo ao desenvolvimento tecnológico e comercial do país. Além disso, apostar no argumento de que em pedido de concessão de patente a Anvisa poderia regular economicamente o mercado farmacêutico seria o mesmo que ignorar instrumentos à disposição do Poder Público outrora desenvolvidos com vistas a regular a saúde pública, principalmente no que concerne ao preço de medicamentos à disposição da população, isto é, o Estado, por meio da Anvisa (secretária-executiva da CMED) dispõe de instrumentos específicos para exercer o controle de preços de medicamentos, no âmbito de sua competência legal e regulamentar. Dessa forma, não é admissível que a Anvisa negue anuência à concessão de patentes farmacêuticas com fundamento na elevação do preço de medicamentos, a pretexto de exercer a regulação econômica do mercado.

\section{REFERÊNCIAS BIBLIOGRÁFICAS}

LICKS, Otto. Registro de medicamentos genéricos na ANVS e infração de patentes. Revista da ABPI, Rio de Janeiro, n. 45, p. 28-35, mar/abr. 2000.

LYARD, Maria Alice Paim. Patentes de Medicamentos, questões atuais. Revista da $A B P I$, Rio de Janeiro, n. 82.

MARQUES, Floriano de Azevedo. A nova regulação estatal e as agências independentes. In: SUNDFELD, Carlos Ari (Org.). Direito administrativo econômico. São Paulo: Malheiros Ed.; SBDP, 2002.

MOREIRA NETO, Diogo de Figueiredo. Reinstitucionalização da ordem econômica no processo de globalização. Cadernos de Direito Constitucional e Ciência Política, Sao Paulo, v. 5, n. 18, p. 87-95, jan./mar. 1997.

(27) Conforme consubstanciado na decisão da Corte Constitucional que permitiu na Itália a patente de remédios: "se o objetivo é a salvaguarda da saúde pública e a patente pode dar lugar a abusos que impediriam satisfazer a esse interesse, a solução não deve consistir na proibição das patentes, mas na regulação adequada, de modo a impedir tais abusos (VASQUEZ, Adolfo. Patentes farmacêuticas, derecho argentino y comparado. In: Derechos intelectuales. Buenos Aires: Astrea, 1991. v. 4 , p. 44). 
REGULAÇÃO econômica do mercado farmacêutico. Brasília: Anvisa, Brasília, maio 2001.

RODRIGUES JUNIOR, Edson Beas. Anuência prévia: integração do direito à saúde aos direitos de propriedade intelectual. Revista dos Tribunais, São Paulo, v. 94, n. 840, p. 84-106. out. 2005.

SALOMÃO FILHO, Calixto; BASSO, Maristela; POLIDO, Fabrício Pasquot. Propriedade intelectual e preços diferenciados de medicamentos essenciais: políticas de saúde públicas para países em desenvolvimento. RDPE, Belo Horizonte, ano 3, n. 11, jul./set. 2005.

TEUBNER, Gunther. Juridificação: noções, características, limites, soluções. Revista de Direito e Economia, Coimbra, 1988.

TOJAL, Sebastião Botto de Barros. A Constituição dirigente e o direito regulatório do Estado social: o direito sanitário. In: ARANHA, Márcio lorio; TOJAL, Sebastião Botto de Barros (Orgs.). Curso de Especialização à distância em Direito Sanitário para Membros do Ministério Público e da Magistratura Federal: Programa de Apoio ao Fortalecimento do Controle Social no SUS, Universidade de Brasília, Faculdade de Direito da UnB, Núcleo de Estudos em Saúde Pública da UnB/CEAM; Escola Nacional de Saúde Pública FIOCRUZ; REFORSUS; Ministério da Saúde.

UNCTAD/ICTSD Resource Book on TRIPS. Part one: nature $f$ obligations, principles and objectives. Geneve, Oct. 2002.

VASQUEZ, Adolfo. Patentes farmacêuticas, derecho argentino y comparado. In: Derechos intelectuales. Buenos Aires: Astrea, 1991. v. 4. 